\section{Technical Report}

\author{
*Corresponding author \\ Xiao-Quan Mao \\ Department of Dental Implant \\ Stomatological Center \\ Affiliate Haikou Hospital \\ Xiangya Medical School \\ Central South University \\ Haikou 570208, Hainan, PR, China \\ E-mail: horse.m@163.com
}

Volume 2 : Issue 2

Article Ref. \#: 1000DOJ2112

\section{Article History}

Received: June $18^{\text {th }}, 2015$

Accepted: July $6^{\text {th }}, 2015$

Published: July $7^{\text {th }}, 2015$

\section{Citation}

Mao XQ, Wang HY, Zhou T, Huang YM, Meng YJ. Combined orthodontic with implant to rehabilitate vertical dimension of occlusion. Dent Open J. 2015; 2(2): 62-65. doi: 10.17140/ DOJ-2-112

\section{Copyright}

(C)2015 Mao XQ. This is an open access article distributed under the Creative Commons Attribution 4.0 International License (CC BY 4.0), which permits unrestricted use, distribution, and reproduction in any medium, provided the original work is properly cited.

\title{
Combined Orthodontic with Implant to Rehabilitate Vertical Dimension of Occlusion
}

\author{
Xiao-Quan Mao ${ }^{{ }^{\star}}$, Hai-Yan Wang ${ }^{2}$, Ting Zhou ${ }^{1}$, Yu-Mei Huang ${ }^{2}$ and Ya-Jiao Meng ${ }^{1}$ \\ ${ }^{1}$ Department of Dental Implant, Stomatological Center, Affiliate Haikou Hospital of Central \\ South University, Xiangya Medical School, Haikou 570208, Hainan, PR, China \\ ${ }^{2}$ Department of Orthodontics, Stomatological Center, Affiliate Haikou Hospital of Central South \\ University, Xiangya Medical School, Haikou 570208, Hainan, PR, China
}

\section{ABSTRACT}

The control of Occlusal Vertical Dimension (OVD) $)^{1}$ is a demanding task for dentists. Establishment of proper occlusal vertical dimension in prosthetic treatment is a important task for clinical procedure. ${ }^{2}$ No methods are considered to be scientifically accurate in determining the reduced OVD in patients with low occlusal vertical dimension. ${ }^{3}$ Various factors need to be considered simultaneously during occlusal rehabilitation, such as vertical dimension of occlusion, occlusal contact pattern, centric relation, esthetics and phonetics. Different philosophies have been documented for occlusal rehabilitation and the choice of treatment plan depends on the skills and experience of the dentist. ${ }^{4}$ The actual basal bone height of the reconstructed maxillary and mandible is relevant to achieve normal OVD for the prosthesis fabricated. ${ }^{5}$ This paper described a case with vertical distance problem in which we combined orthodontics with implantation to rehabilitate vertical dimension of occlusion.

KEYWORDS: Orthodontic; Implant; Rehabilitate.

ABBREVIATIONS: CBCT: Cone-beam computed tomography; OVD: Occlusal Vertical Dimension.

\section{TREATMENT STRATEGY}

A female patient who lost occlusal vertical dimension was treated with this procedure. As shown in Figures 1 and 2, teeth \#25, 35, 36, 37, 38 and 46 were diagnosed as residual roots; teeth \#16, 26 and 27 were diagnosed as elongation; and teeth \#12, 14 and 23 were missing before treatment. The vertical distances between teeth \#16, 26 and the mandibular alveolar ridge were only $2 \mathrm{~mm}$ respectively when the patient bit together. The distal buccal cusp of tooth \#27 almost contacted the mandibular alveolar ridge, as shown in Figures 3 and 4 . There was a space of $3 \mathrm{~mm}$ between teeth 42 and 43. CBCT images showed low-density shadow around the roots of teeth \#11 and 21.

Diagnosis: The low occlusal vertical dimension.

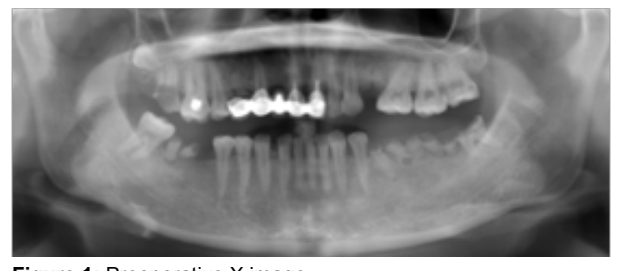

Figure 1: Preoperative $\mathrm{X}$ image

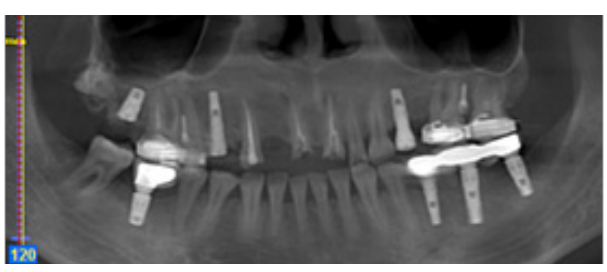

Figure 2: Implantation of postoperative $\mathrm{X}$ image. 


\section{DENTISTRY}

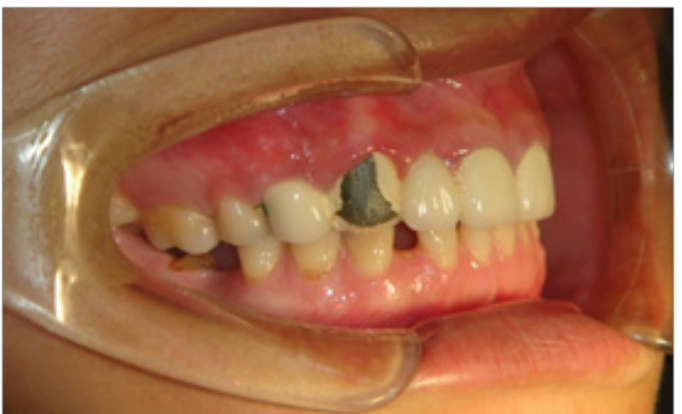

Figure 3: Right occlusion picture.

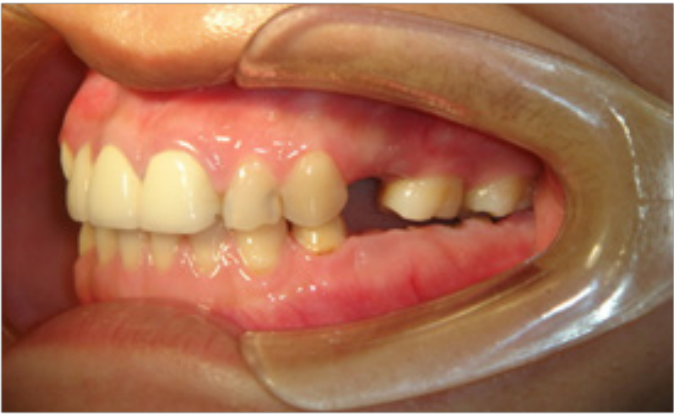

Figure 4: Left occlusion picture.

\section{Orthodontic Treatment Plans}

1. Maxillary flat occlusal guide plate was used to open the bite.

2. Straight wire appliance was applied on the mandibular teeth, leveling and aligning the dentition. Tooth \#47 was moved mesially $3 \mathrm{~mm}$. The space between teeth \#42 and 43 was closed after three months' treatment, as shown in Figure 5.

3. The implant anchorage was used to depress teeth \#16, 26 and 27 in order to provide vertical space. The transpalatal arch was used between teeth \#16 and 26 in order to prevent teeth \#16, 26 and 27 from buccally inclining.

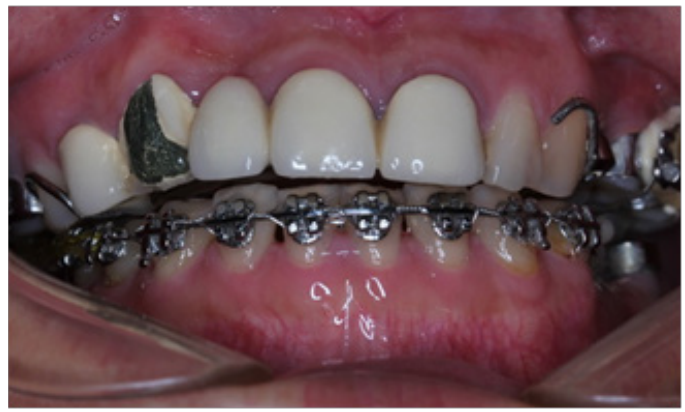

Figure 5: Bing orthodontic.

\section{Implanting Treatment Plans}

1. Immediate implants were implanted on the position of teeth $\# 25,35,36$ and 37 . The residual root of tooth \#38 was saved to maintain the existing vertical distance.

2. Tooth \#46 was implanted after tooth $\# 47$ was moved mesially $3 \mathrm{~mm}$

3. Teeth \#35, 36, 37 and 46 were renovated in crown after bilateral vertical distances of occlusion reached 3-4 $\mathrm{mm}$, as shown in Figure 6.

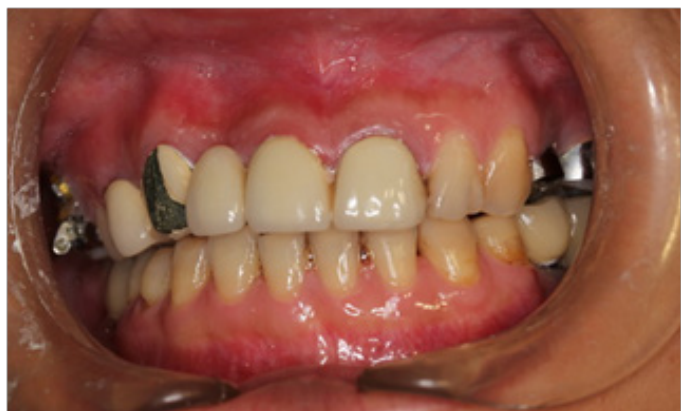

Figure 6: Restoration of mandibular teeth.

\section{ORTHODONTIC PROCEDURES}

Cephalometric analysis indicated a tendency for skeletal Class II malocclusion with a slightly retruded mandible. The labio-lingual inclination of the maxillary and mandibular incisors was almost normal. Removable plane plate was used to open the bite after the splint therapy, ${ }^{6} \mathrm{~A}$ multibracket appliance was mounted on the mandibular teeth to reconstruct occlusion and $0.012-0.018 \times 0.025$ inch NiTi stainless steel archwires were applied for alignment. Implant anchorage were used to depress teeth \#16, 26 and 27 to provide space for rehabilitating vertical dimension of occlusion. The transpalatal arch was used between teeth \#16 and 26 in order to prevent teeth \#16, 26 and 27 from buccally inclining. After ten months treatment, an acceptable occlusion was achieved. The retention phase was accomplished by an invisible mandibular retainer. After one year's retention, the acceptable occlusion was maintained without any relapse or recurrence.

\section{Dental Implant Procedure}

Under local anesthesia, a paracrestal incision was made through the buccal mucosa. A full-thickness flap was retracted and the tension on the mental nerve was carefully avoided. The residual roots of teeth \#25, 35, 36 and 37 were pulled out. Drills with increasing diameters were used to prepare the implant sites, and three implants (Dentis, Korea) were inserted in situ, as shown in Figure 2. The implants were settled down with a torque of $35 \mathrm{~N} \mathrm{~cm}$ and the healing abutments were placed immediately. The cut was closed with $4 / 0$ sutures. Then teeth \#17, 14, 36 were implanted respectively after the orthodontic had been finished. The patient was instructed to use $0.2 \%$ chlorhexidine mouthwash $^{7}$ for one minute twice a day for two weeks, to have soft diet for one week, and to avoid brushing the surgical site for 24 hours. No removable prosthesis was allowed. Sutures were removed after 7 days.

\section{DISCUSSION}

Most studies concluded that denture wearers had only one fifth to one fourth the bite force and masticatory force compared to normal persons with natural dentition. ${ }^{8}$ Edentulous patients with dentures are generally satisfied, but up to $30 \%$ of the patients have complains. ${ }^{9}$ The low occlusal vertical dimension ${ }^{10}$ 


\section{DENTISTRY}

needs to be given definite attention, as it not only affects aesthetics but also causes psychological stress to the affected individuals. It can cause chewing difficulty, temporomandibular joint problems, headaches and facial collapse. Psychosocial problems result from diminished attractive facial appearance, difficulties with speech and avoidance of social contacts. With problems accumulating, they may cause difficulty in getting proper nutrition and the patients' ability to communicate with ease and confidence might be jeopardized. This disorder has an adverse impact on oral health and hampers the quality of patients' life, causing physiologic problems. They suffer from a variety of problems with their dentures, especially with lower denture, such as insufficient stability, retention and pain during mastication.

Treatment goals ${ }^{11}$ is to reconstruct the occlusal relationship, overcoming a series of symptoms caused by small occlusal vertical dimension and restoring patients' confidence in life.

It is essential to resolve the problems associated with the loss of vertical dimension. ${ }^{12}$ How is it to increase the vertical dimension? Cephalometry is a standardized method of assessing dental and facial proportions and their interrelation. ${ }^{13} \mathrm{Re}-$ storative dentistry, orthodontia, and oral surgery are the three disciplines that can help to gain the vertical dimension. ${ }^{14}$

The occlusal vertical dimension was increased to develop sufficient restorative space. ${ }^{13}$ The orthodontic treatment was used to depress maxillary molars to increase occlusal vertical dimension. Bilateral balanced occlusion was established and space for occlusal reconstruction was provided. Missing teeth were replaced by 7 implants, and the function of mastication, appearance and pronunciation were restored in this case. The osseointegration of the implants, the condition of peri-implant mucosa, the function of the prosthesis and esthetics were assessed after 1 week, 1 month, 3 months and 6 months.

It was used for 3 months as a guide to prepare the final restoration. The patient's adaptation to the increased OVD was evaluated. During this period, she was asymptomatic.

\section{CONCLUSION}

The occlusal vertical dimension was successfully rehabilitated with the method which combined orthodontics and implantation.

\section{CONSENT}

Written informed consent was obtained from the patient for publication of this case report and any accompanying images. A copy of the written consent is available for review by the Editorin-Chief of this journal.

\section{COMPETING INTEREST}

The authors declare that they have no competing interests.

\section{AUTHOR'S CONTRIBUTION}

Xiao-Quan Mao is a Dentist who wrote the manuscript.

\section{ACKNOWLEDGEMENTS}

The authors thank Miss Xiao-ni Li for modifying this manuscript and Min-xin Mao for correcting the grammar.

\section{REFERENCES}

1. Shetty M, Joshi N, Prasad DK, Sood S. Complete rehabilitation of a patient with occlusal wear: A case report. J Indian Prosthodont Soc. 2012; 12(3): 191-197. doi: 10.1007/s13191012-0131-z

2. Yamashita S, Shimizu M, Katada H. A newly proposed method to predict optimum occlusal vertical dimension. J Prosthodont. 2015. doi: 10.1111/jopr.12223

3. Basnet BB, Parajuli PK, Singh RK, Suwal P, Shrestha P, Baral D. An anthropometric study to evaluate the correlation between the occlusal vertical dimension and length of the thumb. Clin Cosmet Investig Dent. 2015; 3(7): 33-39. doi: 10.2147/CCIDE. S75872

4. Rivera-Morales WC, Mohl ND. Restoration of the vertical dimension of occlusion in the severely worn out dentition. Dent Clin North Am. 1992; 36(3): 651-664.

5. Akinbami BO, Nsirim PE. Analysis of occlusal vertical dimension and mandibular Basal bone height in a nigerian population. Anat Res Int. 2014; 2014: 584508.doi: 10.1155/2014/584508

6. Kurt H, Oztaş E, Gençel B, Taşan DA, Oztaş D. An adult case of temporomandibular joint osteoarthritis treated with splint therapy and the subsequent orthodontic occlusal reconstruction. Contemp Clin Dent. 2011; 2(4): 364-367. doi: 10.4103/0976-237X.91805

7. Laino L, Iezzi G, Piattelli A, Muzio LL, Cicciù M. Vertical ridge augmentation of the atrophic posterior mandible with sandwich technique: Bone block from the chin area versus corticocancellous bone block allograft-clinical and histological prospective randomized controlled study. Biomed Res Int. 2014; 2014: 982104. doi: 10.1155/2014/982104

8. Tripathi G, Ponnanna AA, Rajwadha N, Chhaparia N, Sharma A, Anant M. Comparative evaluation of maximum bite force in dentulous and edentulous individuals with different facial forms. J Clin Diagn Res. 2014; 8(9): ZC37-ZC40. doi: 10.7860/ JCDR/2014/8801.4837

9. Shah FK, Gebreel A, Elshokouki AH, Habib AA, Porwal A. Comparison of immediate complete denture, tooth and implant-supported overdenture on vertical dimension and muscle 


\section{DENTISTRY}

activity. J Adv Prosthodont. 2012; 4(2): 61-71. doi: 10.4047/ jap.2012.4.2.61

10. Bansal R, Jain A, Mittal S, Kumar T. Full mouth rehabilitation in a medically compromised patient with fluorosis. J Clin Diagn Res. 2014; 8(7): ZD22-ZD24. doi: 10.7860/ JCDR/2014/9148.4594

11. Hermanides L, Larson K. Maxillary esthetics, mandibular function: a rationale for predictable treatment of the moderately worn dentition. Compend Contin Educ Dent. 2014; 35(8): 583587.

12. Rajesh P, Prasad M, Haldal S. Full mouth rehabilitation of a patient with amelogenesis imperfecta: A case report. J Int Oral Health. 2014; 6(4): 76-79.

13. Zielak JC, Gulin Neto D, da Cunha LF, Deliberador TM, Giovanini AF. Cephalometric approach to the occlusal vertical dimension reestablishment. Case Rep Dent. 2014; 2014: 920840. doi: 10.1155/2014/920840

14. Ergun G, Yucel AS. Full-mouth rehabilitation of a patient with severe deep bite: A clinical report. J Prosthodont. 2014; 23(5): 406-411. doi: 10.1111/jopr.12113 